\title{
Structural domains and molecular lifestyles of insulin and its precursors in the pancreatic Beta cell*
}

\author{
P.A.Halban \\ Laboratoires de Recherche Louis Jeantet, University of Geneva Medical Centre, Geneva, Switzerland
}

\begin{abstract}
Summary. Insulin is both produced and degraded within the pancreatic Beta cell. Production involves the synthesis of the initial insulin precursor preproinsulin, which is converted to proinsulin shortly after (or during) translocation into the lumen of the rough endoplasmic reticulum. Proinsulin is then transported to the trans-cisternae of the Golgi complex where it is directed towards nascent secretory granules. Conversion of proinsulin to insulin and C-peptide arises within secretory granules, and is dependent upon their acidification. Granule contents are discharged by exocytosis in response to an appropriate stimulus. This represents the regulated secretory pathway to which more than $99 \%$ of proinsulin is directed in Beta cells of a healthy individual. An alternative route also exists in the Beta cell, the constitutive secretory pathway. It involves the rapid transfer of products from the Golgi complex to the plasma membrane for immediate release, with, it is supposed,
\end{abstract}

little occasion for prohormone conversion. Even if delivered appropriately to secretory granules, not all insulin is released; some is degraded by fusion of granules with lysosomes (crinophagy). Eachevent in the molecular lifestyles of insulin and its precursors in the Beta cell will be seen to be governed by their own discrete functional domains. The identification and characterisation of these protein domains will help elucidate the steps responsible for delivery of proinsulin to secretory granules and conversion to insulin. Understanding the molecular mechanism of these steps may, in turn, help to explain defective insulin production in certain disease states including diabetes mellitus.

Key words: Preproinsulin, proinsulin, insulin, C-peptide, biosynthesis, precursor processing, protein trafficking, protein degradation, pancreatic Beta cell.

\section{The essential features of insulin synthesis and degradation in the pancreatic Beta cell}

Insulin biosynthesis by the pancreatic Beta cell involves the combination of the vectorial transfer of precursors from one organelle to the next, and the proteolytic conversion of these precursors. Insulin degradation within the Beta cell similarly involves an interorganelle transfer event (fusion of granules and lysosomes) followed by degradation (proteolytic attack). For both biosynthesis and degradation, it has become evident that insulin and its precursors are not passive participants. On the contrary, they play a dominant role in their own fate by virtue of discrete functional domains which are essential features of their three-dimensional protein structure. This is an example of molecular self-determination. Other domains will clearly come into play once insulin has been released from the Beta cell, including most notably those implicated in bind-

* Presented in part as the 25th Minkowski Prize Lecture at the EASD Annual Meeting. Copenhagen, September, 1990 ing of insulin by its receptor, but these domains will only be discussed if and when they impinge upon the central topics of this Review.

Before discussing each domain in detail, it is appropriate to recall the essential features of the insulin biosynthetic cascade, as outlined in Figure 1. Our knowledge of this pathway is based largely upon the pioneering morphological studies of Palade [1] and, more recently, and more specifically for the pancreatic Beta cell, the seminal work of Orci [2,3]. Parallel studies on the biochemistry of insulin synthesis were initiated by the classic studies of Steiner showing that the two insulin chains are synthesised as a single chain, high molecular weight precursor, proinsulin and some years later, it was shown that proinsulin itself arises from a precursor, preproinsulin [4]. The linear array of the peptide domains of preproinsulin are shown in Figure 2, and the steps involved in its processing to proinsulin and thereafter to insulin are illustrated in Figure 3.

Insulin synthesis commences with the transcription of the insulin gene. Although transcription will not be dis- 


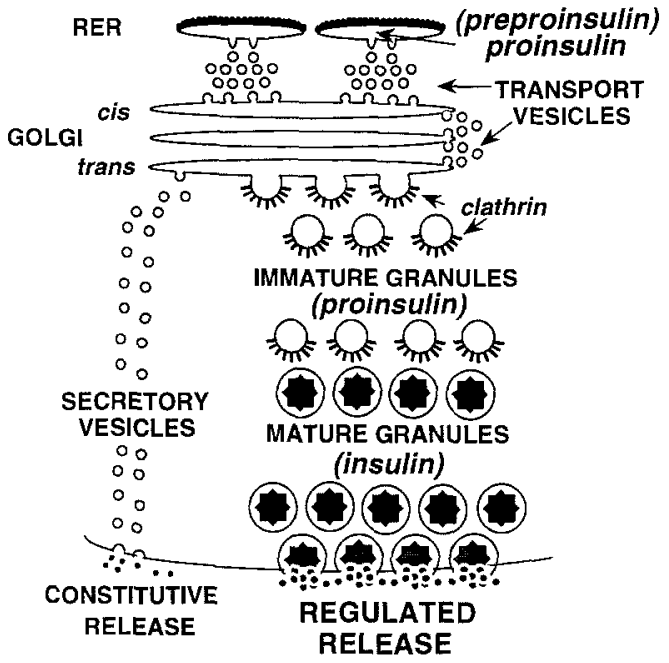

Fig. 1. The insulin biosynthetic pathway. The events leading from the conversion of preproinsulin to proinsulin in the lumen of the rough endoplasmic reticulum (RER), through to the storage of insulin in mature granules and its release by exocytosis are depicted in simplified form. Under normal circumstances more than $99 \%$ of proinsulin will be directed to secretory granules for regulated release. The maturation of the secretory granule is described in greater detail in Figure 4, and insulin degradation (crinophagy) is illustrated in Figure 6

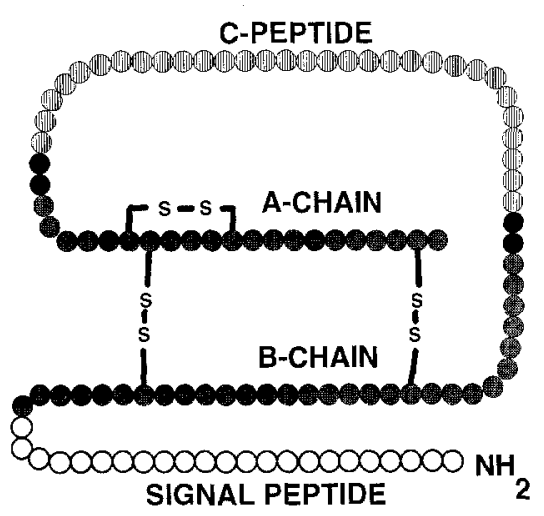

Fig. 2. The linear arrangement of the constituent peptides of preproinsulin. The pairs of basic amino acids linking the insulin chains to the C-peptide are shown in black

cussed in any detail, there are a couple of features of this initial step in the synthetic cascade which merit our attention. In the adult animal, transcription of the insulin gene appears to be restricted essentially to the pancreatic Beta cell [5]. The upstream cis-elements and trans-acting factors responsible for this exquisite tissue specificity are currently the subject of active scrutiny. In addition to such specificity, transcription of the insulin gene is regulated by the cell's environment, and principally by glucose and cyclic AMP [6]. The primary transcript of most insulin genes has two introns which must be excised before the mature mRNA can move to the cytoplasm for translation. Transcription, the gateway to insulin biosynthesis, is thus itself both regulated and dependent upon the refinement of molecular information implicit in splicing of the primary transcript.
Post-transcriptional events in the insulin biosynthetic pathway have been the subject of a number of Reviews [2-4] and only the salient features will be recalled here. Translation of the insulin mRNA occurs on the Beta cell rough endoplasmic reticulum (RER). Translation, like transcription, is regulated by a number of factors including glucose and cAMP $[4,6]$. The nascent peptide chain is sequestered into the lumen of the RER and the signal peptide is cleaved by signal peptidase. Both events are discussed in greater detail below in the context of the signal peptide structural domains. Proinsulin is transported from the RER to the cis-cisternae of the Golgi complex, and from one cisterna to the next, in small vesicles. By analogy with other cells, it is assumed that the formation of these vesicles depends upon a coating with $\beta$-COP (coat protein) [7], a protein displaying homology with one of the adaptins implicated in the coating of membranes with clathrin but not itself clathrin, and that they lose this coat before fusing with the target organelle. How such vesicles find their way from one station to the next remains quite mysterious. It is known, however, that RER to Golgi transfer in the Beta cell is energy dependent [8] and that it
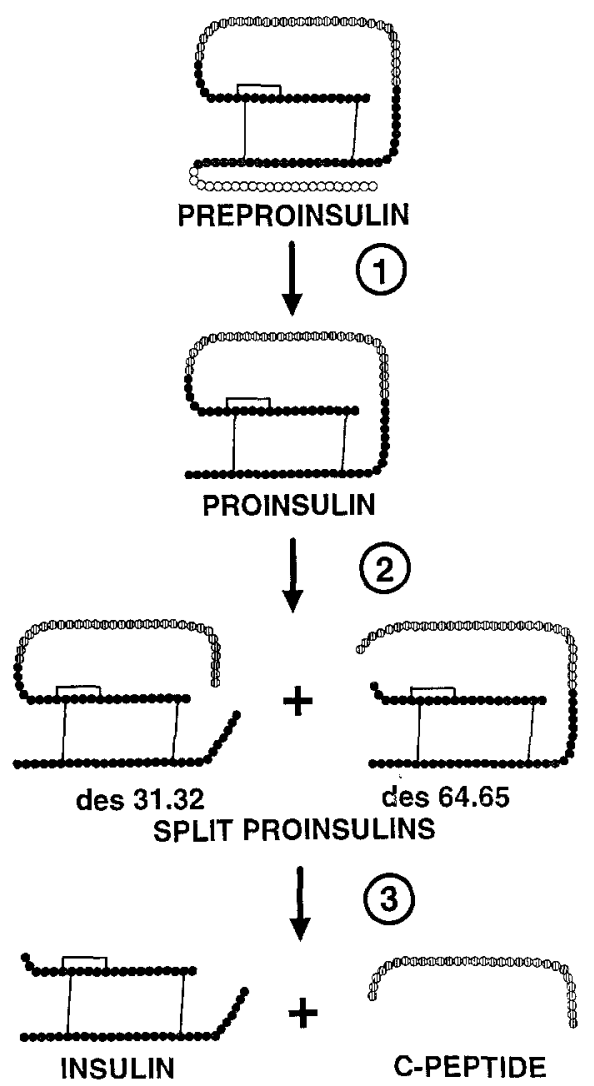

Fig.3. Processing of insulin precursors: (1) Preproinsulin is converted to proinsulin by signal peptidase in the lumen of the rough endoplasmic reticulum. This occurs for the most part before translation is complete; (2) The initial step in proinsulin conversion is its cleavage by an endoprotease at either the B-chain/C-peptide or the $\mathrm{C}$-peptide/A-chain junction, followed by trimming of residual C-terminal basic amino acids by carboxypeptidase $\mathrm{H}$. The products are the two possible split proinsulin conversion intermediates; (3) A second round of endoproteolytic attack and carboxypeptidase trimming of each of the two intermediates generates mature insulin and C-peptide 


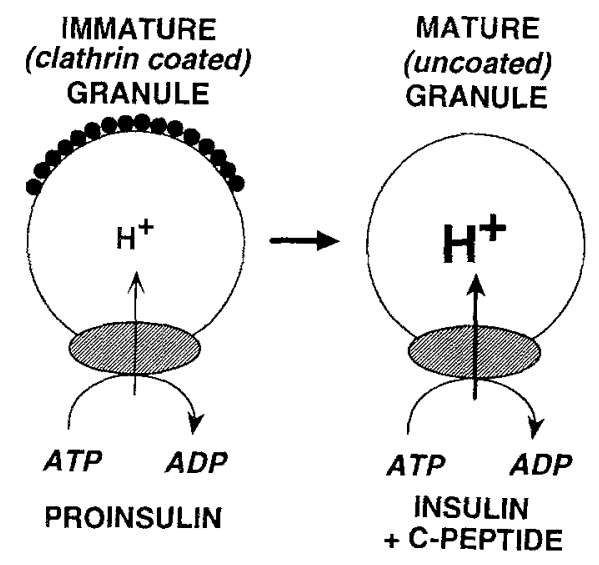

Fig.4. Maturation of the Beta-cell secretory granule. Maturation involves removal of the clathrin coat and progressive acidification of the granule interior by action of an ATP-dependent proton pump. Such acidification assures an appropriate environment for full activity of the conversion enzymes. There is indirect evidence to suggest that uncoating is dependent upon proinsulin conversion

Table 1. Characteristics of regulated and constitutive secretory pathways

\begin{tabular}{lll}
\hline Regulated & & Constitutive \\
\hline 30 min to days & Transit time & Approx. 20 min \\
Yes & Storage depot & No \\
Yes & Control by secretagogues & No \\
Yes & Proprotein conversion & $? ?$ \\
\hline
\end{tabular}

The regulated secretory pathway involves packaging of a prohormone into granules, intragranular conversion, storage, or release in response to a secretagogue. The constitutive pathway involves the rapid, non-regulated release of products from secretory vesicles without the possibility of storage. Although some proproteins can be converted via the constitutive pathway, the extent of conversion of proinsulin if misrouted to the constitutive pathway has yet to be studied in detail

is inhibited by agents which interfere with the cytoskeleton [9]. Again by analogy with other cell types, we can assume that both RER-Golgi and inter-Golgi cisternal traffic are dependent upon G-proteins [10] and other accessory proteins $[11,12]$ including the N-ethylmaleimide-sensitive fusion (NSF) protein [13]. The end-station of this particular series of transfer events is the transGolgi.

The trans-Golgi, or trans-Golgi network [14], is the compartment in which proinsulin will become sorted to secretory granules [15], and as such destined for processing and release via the regulated secretory pathway. This sorting event, which will be discussed further, is central to the normal differentiated function of the Beta cell [16] and, as such, to the well-being of the individual. The reason lies in the fundamental differences between the regulated and constitutive secretory pathways [16-18] as outlined in Table 1. In the Beta cell, the regulated pathway involves packaging of proinsulin into secretory granules in which it will be converted to insulin [19]. The granules serve as the storage depot from which insulin (and residual proinsulin) can be mobilised (by exocytosis) at the call of a secretagogue. If not secreted, insulin can be degraded by fusion of granules and lysosomes (crinophagy) [20,21], making the granular storage depot a second important Beta cell "crossroads". Even if a newly synthesised proinsulin molecule can be secreted rapidly via the regulated pathway, other proinsulin and predominantly insulin molecules may reside in the storage depot for days before being released or degraded. What a contrast to the constitutive pathway, in which newly synthesised proteins are introduced into small secretory vesicles to be rapidly (estimated transit time from Golgi complex to plasma membrane of the order of $10-20 \mathrm{~min}[17,18,22])$ and invariably (i.e. without the possibility for modulation by secretagogues) discharged by exocytosis. There is no storage depot in the constitutive pathway, and no degradative compartment emanating from this pathway has been described. It is, however, possible to envisage the fusion of constitutive secretory vesicles with a lysosomal compartment in much the same way as endosomes can deliver their contents to lysosomes.

Proinsulin is concentrated in regions of the trans-Golgi identified by the presence of a clathrin coat on their cytosolic face $[2,3]$. The physiological role of clathrin in the context of secretory pathways remains unclear, but it is assumed that it must be implicated in the formation of vesicles/granules from the trans-Golgi. Intriguingly, cells with the regulated pathway display a unique pattern of clathrin light chain isoforms, which in itself suggests a special sort of clathrin-coating for the regulated secretory pathway [23]. The earliest detectable (immature) granules still carry a partial coating of clathrin on the cytosolic face of their limiting membrane $[2,3]$. Although there has been the suggestion of precocious conversion of proinsulin to a partially cleaved intermediate in the Golgi complex [24], it is generally accepted that the bulk of conversion to insulin arises within immature granules [19]. Conversion of proinsulin is not an isolated event. Rather, two other changes to the immature granule occur at the same time: removal of the clathrin coat and acidification of the granule milieu (Fig.4). Granule acidification is the responsibility of an ATP-dependent proton pump [25], and in the Beta cell, the mature granule is more acidic than its immature counterpart [3]. The conversion enzymes display an acidic pH optimum (although one of the candidate endoproteases is quite active even at neutral $\mathrm{pH}$ [24]) and such ATP-dependent acidification of the granule milieu is therefore a prerequisite for efficient conversion [26]. The loss of the clathrin coat may, in turn, be dependent upon conversion. If conversion is blocked (by the incorporation of analogues of arginine and lysine into newly synthesised proinsulin), so is clathrin uncoating [27]. How conversion and uncoating are linked (if indeed they are) is unclear. If one assumes that the cytoplasmic tail of the putative "sorting" receptor (the nature of which will be discussed in detail below) is bound by adaptins and in turn clathrin, it is possible to imagine release of proinsulin from the receptor (due to acidification and/or conversion) causing a structural change transmitted to the cytoplasmic tail with consequent loss of clathrin.

Delivery to constitutive vesicles is presumed to be by default; if a secretory or integral membrane protein has not been selected for another destination (return to the 
ER, retention in the Golgi complex, dispatch to lysosomes, etc) then it will end up in constitutive vesicles [17, 18]. The constitutive pathway is thus typically viewed as a rather non-specific dustbin. Yet when one considers its central role in delivering proteins, including receptors, to the plasma membrane, and in the secretion of a large spectrum of proteins, it is evident that such a view fails to do this pathway justice.

Conversion of prohormone to hormone is considered a prerogative of the regulated pathway, and is commonly thought not to occur if a prohormone should find itself secreted by the constitutive pathway $[17,18]$. If proinsulin were to be diverted to the constitutive pathway, it is thus assumed that it would be rapidly released in the unprocessed form. As we shall see, this prediction has important implications for our understanding of Beta-cell function in health and disease. This may, however, be a gross oversimplification. The constitutive pathway is not enzymatically inert. Proteins handled by this pathway are thus known to be processed in much the same way as a prohormone in secretory granules. Two examples will suffice. Proalbumin to albumin conversion involves cleavage at a pair of basic residues [28], and conversion of the insulin proreceptor to the mature $\alpha$ - and $\beta$-subunits involves cleavage at a site presenting four basic residues [29]. In both these cases, mutations altering just one of the basic amino acids inhibits conversion in vivo (in man) $[28,29]$. Although just where such conversion occurs (Golgi complex or constitutive vesicles) and what enzymes are involved remain unclear, it is already apparent that there is considerable overlap in the conversion machinery of the regulated and the constitutive pathways [30,31], and current experiments in our laboratory would suggest that proinsulin itself may be subject to limited conversion when it is synthesised in transfected hepatoma cells which express only the constitutive pathway (Vollenweider and Halban, unpublished data).

Release (exocytosis) of both constitutive vesicle and secretory granule contents occurs by fusion with the plasma membrane $[2,3,17,18]$. For the purposes of this Review it will be necessary only to recall the dramatic difference in kinetics of release by the two secretory pathways and the fact that proinsulin is expected to be the major secretory product of the constitutive pathway and insulin of the regulated pathway.

\section{Structural domains of insulin and its precursors}

\section{The signal peptide of preproinsulin}

Signal peptides of secretory proteins must present three major functional domains essential for: (1) binding to the signal recognition particle; (2) translocation across the membrane of the RER; (3) presentation for cleavage by signal peptidase $[32,33]$. Although the comparison of the primary sequences of signal peptides from a variety of preproteins fails to indicate any obvious consensus there is a well-established general requirement for an acidic $\mathrm{N}$-terminus, a hydrophobic central domain and a polar C-terminal region $[34,35]$. The dependence upon these domains is exemplified by the demonstration that even point mutations can lead to impaired translocation and/or prevent cleavage by signal peptidase [36].

If targetting to the RER or translocation across the RER membrane were to be impaired by a mutation, preproinsulin would be synthesised on free ribosomes and discharged to the cytosol. Such mutant preproinsulin would most probably be degraded quite rapidly, since it would be considered as an abnormal cytosolic protein; in any event it would not be secreted. By contrast, a change only to the domain recognised by signal peptidase would lead to the appearance of unprocessed preproinsulin in the lumen of the RER. It is probable that such mutant, unprocessed preproinsulin would be recognised as a "faulty" product leading to its destruction in the "pre-Golgi" degradative compartment. Although the precise location of this compartment remains unclear, it is thought to be active in most cells and serves as a quality-control filter for newly synthesised secretory proteins [37].

\section{Structural domains of proinsulin}

The folding of newly synthesised proinsulin. Preproinsulin is translocated across the ER membrane in an extended form. After removal of the signal peptide and completion of translation it is expected, by analogy with other secretory proteins, that proinsulin will start to assume its secondary and tertiary structure within the RER. Although disulphide bridge formation and even correct folding into native tertiary configuration can occur for many proteins (including proinsulin) in free solution, within the RER these events depend upon the interaction of the secretory protein with resident ER proteins [38-40]. These include protein disulphide isomerase (PDI), an enzyme implicated in disulphide bridge formation [41] and GRP78 (BiP) a protein often implicated in the folding of proteins $[38,39]$. The relevance of these proteins to proinsulin folding in the RER of the Beta cell remains untested experimentally.

The first structural domains of proinsulin to become involved in the synthetic pathway will thus be those required for recognition by or association with the relevant ER resident proteins. The nature of these domains remains unknown at present.

Targetting to the secretory granule (regulated pathway). The Beta cell normally sorts more than $99 \%$ of newly synthesised proinsulin to secretory granules for regulated release [42]. Although the precise mechanism of this sorting event remains to be elucidated, a working model can be proposed based upon a variety of experimental data. At the morphological level, Orci demonstrated some years ago that proinsulin can be found localised to the inner face of Golgi membranes, suggesting the possibility of its association with a receptor [43]. This receptor would be involved in targetting to the regulated secretory pathway. The penultimate event before granule formation is the appearance of proinsulin concentrated in regions of the trans-Golgi distinguished by the presence of clathrin on the cytosolic face of their membranes [2,3]. These regions 


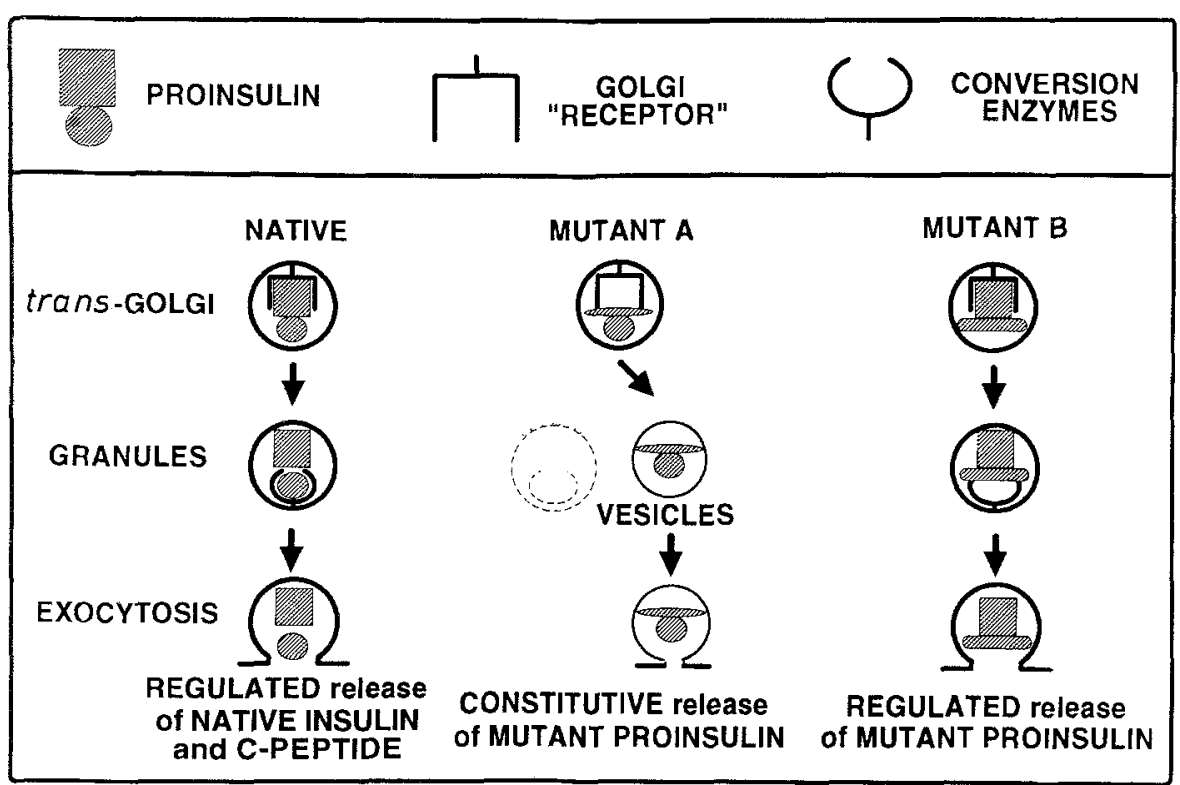

Fig.5. Role of proinsulin domains in trafficking and processing. It is suggested that the "sorting" domain(s) of proinsulin is recognised in the trans-Golgi by a receptor responsible for targetting proinsulin to granules, and the regulated secretory pathway. Such receptors have yet to be identified in any secretory cell type. Once in granules, the "conversion" domain(s) will allow for the complete conversion of proinsulin to insulin. The overall result will be the regulated release of insulin. Alterations to these domains will lead to faulty targetting and/or conversion as shown under Mutant $\mathrm{A}$ (mutation of the "sorting" domain) and $\mathbf{B}$ (mutation of the "conversion" domain). It is assumed that any proinsulin diverted to constitutive secretory vesicles will not be converted; some conversion may nonetheless occur in these organelles then bud off to form the immature, clathrin-coated granule. The resemblance to receptor-mediated endocytosis of hormones via clathrin coated pits is quite striking [2], and strengthens the concept of targetting to granules being a receptor-mediated event. However attractive the theory, the putative regulated pathway receptor has proved to be quite elusive and has yet to be identified. The only promising candidates (members of a 25 kilodalton family of proteins found only in cells expressing the regulated pathway) [44] have subsequently been found not to possess all the features expected of the receptor. They are, indeed, not even membrane bound. One reason why it has proved so hard to identify this elusive receptor may be its very nature. Based upon a series of experiments involving the expression of foreign secretory proteins in regulated secretory cells (including proinsulin in cells of the AtT20 transformed pituitary corticotroph line [45]), it must be concluded that the "receptor" will display extraordinarily broad specificity. It must thus be able to recognise most if not all proteins destined for the regulated pathway and yet remain sufficiently selective to exclude inappropriate proteins from the target pathway. The problem is further confounded by the fact that although a consensus domain on prohormones sorted to the regulated pathway by transfected AtT20 cells has been identified [46] it is not known whether it is of any relevance to the sorting process. Finally, it is known that proteins in secretory granules condense to form electron dense material. Such condensation can certainly occur in the trans-Golgi and even in the RER under exceptional circumstances [47], which has led to the hypothesis that condensation is an essential feature of the sorting process [18]. Does the receptor have to recognise such condensed material? If so, the structural domains presented on the solvent-face of protein aggregates would be the ones of interest. Until we understand how proteins aggregate in the secretory pathway it will not be possible to predict for any given protein (including proinsulin) just which regions of the molecule will be implicated in such structural domains.
Even if the sorting machinery is not yet well understood, it will become apparent from the above discussion that there will certainly be structural constraints imposed upon a protein destined for the regulated pathway. It must, most probably, be able to condense in an aggregated form within the trans-Golgi (or possibly at an earlier step) and some feature(s) of the condensed product must be recognised by the proposed receptor for targetting to granules. How can we determine which regions of the proinsulin molecule are involved? The most obvious approach is to examine the handling of mutant proinsulin molecules in the secretory pathway. The predicted outcome of such experiments is depicted in Figure 5 (Mutant A). If the mutation in question alters a domain important for aggregation/condensation or binding by the regulated pathway receptor (and these domains may turn out to be one and the same) then the modified proinsulin molecule should no longer be targetted to secretory granules. It should, on the contrary, be secreted via the constitutive pathway.

At the practical level, such experiments depend upon expressing the mutant proinsulin gene following its transfection into suitable cells. The chosen cells must be transformed to facilitate transfection and selection of stable clones. It is merely assumed that the cell lines employed for this purpose will be truly representative of the situation within the native Beta cell. The observation of altered handling of proinsulin in transformed Beta cells (see below), certainly raises questions about the validity of extrapolating data from transformed non-Beta cells. Nonetheless, using such an approach, it has been shown that the C-peptide is not required for efficient sorting to granules in transfected AtT20 cells [48]. Indeed, to date only one mutant proinsulin has been shown to be poorly sorted to the regulated pathway. It was first identified when the mutant allele from a patient with an unusual form of familial hyperproinsulinaemia was sequenced. Unlike other cases in which one of the basic residues involved in proinsulin conversion had become substituted (see below), a single amino acid substitution was found far 
removed from the two sites of conversion. This mutant proinsulin was predicted to have aspartic acid rather than histidine at position 10 of the insulin B-chain. In parallel studies, Steiner's group expressed the mutant (B10 Asp) human insulin gene in transgenic mice and then studied its handling in the islets of these mice [49]; we opted to express the B10 Asp rat insulin II gene in transfected AtT20 (pituitary corticotroph) cells [50]. Both studies showed that B10 Asp proinsulin is partially diverted from the regulated to the constitutive pathway, and this has been confirmed in an independent study of AtT20 cells transfected with the mutant human proinsulin gene [51]. The B10 Asp mutation does thus indeed behave like Mutant A in Figure 5. It is important to stress, however, that the diversion of $\mathrm{B} 10$ Asp proinsulin is only partial (representing some $20-30 \%$ of newly synthesised mutant proinsulin) and that there seems to be extensive pre-Golgi degradation of the mutant molecule $[49,50]$. The data do implicate B10 His in the normally efficient targetting of proinsulin to granules. We are, however, still far from understanding the precise role of this residue. The only suggestions to date $[49,50]$ are inspired by our knowledge of the physico-chemical and biological properties of the insulin molecule outside of the Beta cell. They may well have no significance for the handling of proinsulin in the Beta cell secretory pathway. $\mathrm{B} 10 \mathrm{His}$ is, thus, known to be essential for the co-ordination of $\mathrm{Zn}^{++}$required for insulin (and, it is presumed, proinsulin) hexamerisation [52, 53]. Could it be that the formation of $\mathrm{Zn}$-proinsulin hexamers is important for targetting to the regulated pathway? It is important to distinguish here between the essentially anarchic aggregation of a protein leading to its precipitation and thus its condensation, and the highly organised molecular interactions involved in protein oligomerisation. Insulin may be relatively unusual in being able to oligomerise in an ordered fashion, and this may be of greater relevance to storage in the crystal state (see below) than to targetting in the trans-Golgi. The second hypothesis to explain the unusual handling of B10 Asp proinsulin in secretory cells is based upon studies on the biological activity of insulins modified at this site. B10 Asp insulin is bound more avidly by the insulin receptor than is native insulin [54]. This has led Steiner and colleagues [49] to postulate that B10 Asp proinsulin is bound by nascent insulin receptors in the trans-Golgi. Native proinsulin would, by contrast, not be bound in this way. The insulin receptor is destined for the cell surface to which it will be delivered in constitutive vesicles. It is thus suggested that B10 Asp proinsulin is "hijacked" by the insulin receptor to the constitutive pathway. A major assumption intrinsic to this hypothesis is that the insulin proreceptor will have been cleaved (a prerequisite for binding insulin) in the trans-Golgi - this has never been demonstrated. Experiments are currently under way to test these two hypotheses. We (Gross, Villa-Komaroff and Halban, unpublished data) and others [51] have thus found that B9 Asp proinsulin is well sorted into the regulated pathway in transfected AtT20 cells. This mutant proinsulin cannot even dimerise (due to charge interference on the neighbouring proinsulin monomer [55]), yet alone form hexamers. Its secretion by the regulated pathway would sug- gest that oligomerisation is not a prerequisite for sorting. This is not particularly surprising since guinea-pig insulin, which displays asparagine instead of histidine at position $\mathrm{B} 10$, cannot form $\mathrm{Zn}$-hexamers and yet seems to be targetted perfectly well to secretory granules.

Interpretation of the data for the sorting of B10 Asp proinsulin is, however, complicated by our recent observation that in one particular clone of AtT20 cells transfected with the B10 Asp mutant gene there was no detectable diversion whatsoever to the constitutive pathway [56]. This clone produced 50-times more immunoreactive insulin than the previous clones studied. It is possible that the higher local concentration of the mutant proinsulin in the trans-Golgi prevents the partial diversion seen in the other clones. This in turn suggests that B10 Asp proinsulin may have different aggregation/condensation properties than native proinsulin, resulting in the escape of some non-aggregated proinsulin to the constitutive pathway unless the local concentration of the mutant form is exceedingly high.

Expected features of the "sorting" domain. Based upon the above considerations, we can predict what features to expect of the structural domain(s) implicated in the sorting of proinsulin to the regulated pathway. It is assumed that proinsulin molecules must aggregate in the trans-Golgi. This condensation event is regarded as being different to oligomerisation, but it cannot be excluded that the proinsulin hexamer condenses more effectively than monomeric proinsulin. The structural domains important for condensation must ensure that aggregation of proinsulin molecules results in presentation of hydrophobic domains at the surface of the aggregates, thereby facilitating precipitation in an aqueous environment. Both the sites of contact between proinsulin molecules and those domains to be found at the surface of the aggregates will thus play equally important roles. Proinsulin is not the only molecule destined for the secretory granule. On the contrary, the granule is known to contain a complex mixture of proteins, including the conversion enzymes [57]. The co-condensation of proinsulin with these other granule constituents is clearly likely although not mandatory [18]. It is also possible that other accessory (chaperone) proteins serve to promote condensation. Proinsulin may therefore present structural domains necessary for interaction with other proteins. Finally, even if a specific "regulated pathway receptor" has yet to be identified, its existence remains entirely in keeping with everything that is known about the sorting process. It is thus possible that one proinsulin domain may be recognised by the putative receptor. Such a domain could well be the same as the one proposed for the region of the molecule exposed to the solvent when proinsulin is in a condensed state.

It will be apparent from this discussion that the local environment, in its most general context, will be critical for effective proinsulin sorting. This will include not only the other proteins destined for the secretory granule, and the putative receptor, but also the ionic environment. It is thus more than likely that the local $\mathrm{pH}$ and the concentration of divalent cations will affect the physico-chemical state of proinsulin. If, as has been suggested, proinsulin can hexa- 
merise in the trans-Golgi, this would require an adequate concentration of $\mathrm{Zn}^{++}$[53]. By analogy with other secretory proteins, proinsulin condensation may depend upon the local $\mathrm{Ca}^{++}$concentration [58]. The presence of negatively charged regions which become masked by divalent cations may thus be an additional feature of the sorting domain(s). The study of the proinsulin "sorting" domains and of the sorting machinery itself will be greatly facilitated by the use of cell-free model systems $[58,59]$.

Conversion of proinsulin to insulin. Proinsulin has two pairs of basic residues at which cleavage must occur to generate mature insulin: Arg.Arg links the insulin B-chain to C-peptide, and Lys.Arg the C-peptide to the A-chain [4]. Two endoproteases are thought to be involved in proinsulin cleavage, with each displaying a preference for just one of the two conversion sites [24]. The complete conversion of proinsulin (Fig. 3) involves cleavage at one or the other of the two sites, followed by trimming of residual C-terminal basic residues by carboxypeptidase $H[60]$. A second round of endoprotease cleavage and carboxypeptidase trimming then generates mature insulin $[4,24]$. It will be interesting to see to what extent the prohormone endoproteases of the regulated pathway differ from their counterparts in the constitutive pathway and whether there are cell-type specific endoproteases. The mammalian equivalents of the yeast KEX2 endoprotease are currently being cloned. Three gene products have been identified to date. Furin [61] is thought to be the conversion endopeptidase of the constitutive pathway, whereas the two "PC" endopeptidases are believed to be responsible for prohormone conversion in the regulated pathway $[62$, 63].

The structural domains of the proinsulin molecule implicated in its conversion although far from being totally defined, are certainly better understood than those involved in its sorting to the regulated pathway. The minimal requirements are that a pair of basic residues is present at the site of cleavage. This was confirmed by replacing Arg and Lys in newly synthesised proinsulin with the analogues canavanine and thialysine [64]. The conversion of the modified proinsulin was severely compromised. The replacement (by site-directed mutagenesis) of just one of the two arginines at the B-chain/C-peptide junction with a glycine prevented cleavage by semi-purified conversion endoproteases [65]. Finally, there have been a small number of cases of familial hyperproinsulinaemia in which just one basic amino acid at one of the two conversion sites has been shown to be replaced, leading to the appearance of partially cleaved proinsulin in the circulation [66].

By analogy with the conversion of other prohormones, it was predicted that merely having a pair of basic residues on the surface of proinsulin would not in itself be sufficient to ensure endoproteolysis. This has been confirmed experimentally. As for the study of the "sorting" domains, it has also been possible to probe the "conversion" domain(s) by introducing mutations into the insulin gene by site-directed mutagenesis, and then following conversion kinetics after transfection of the mutant gene into an appropriate secretory cell [67]. A change to the "conversion" domain should lead to the regulated release of the mutant proinsulin (see Mutant B, Fig. 5). For the purposes of these studies it has again been assumed that the cell type used for transfection is truly representative of the natural situation within the Beta cell secretory granule; this has yet to be verified experimentally. Even if the conversion machinery may not be "universal", as exemplified by the tissue-specific generation of unique conversion products arising from a single, common, precursor (i.e. the tissue specific cleavage of proopiomelanocortin (POMC) [68]), the conversion of a prohormone in an ectopic site is not uncommon. Proinsulin can thus be converted to insulin in transfected AtT20 cells [45, 50,67], and POMC can be cleaved at discrete sites if expressed in transformed Beta cells (RIN cells) [69].

The comparison of all known C-peptide sequences showed a remarkable conservation of an acidic domain immediately after the B-chain/C-peptide junction. If this domain (consisting of the first 4 amino acids of C-peptide) is deleted, conversion of the mutant proinsulin in transfected AtT20 cells is inhibited. As predicted for a mutation only affecting conversion, but not sorting to the regulated pathway, this particular mutant proinsulin is released via the regulated pathway (Mutant B, Fig. 5). It is important to stress that this mutant proinsulin still has the normal complement of basic amino acids at the two conversion sites. It is therefore concluded that the deleted Cpeptide domain must be implicated in the presentation of the basic residues to the endoproteases. The removal of a major segment of C-peptide has also been shown to prevent conversion by endoproteases in vitro [65].

Regions of the proinsulin molecule possibly implicated in the "conversion" domain. It will be seen that conversion depends in an absolute fashion upon the presence of the appropriate pairs of basic residues at the two sites of conversion. In addition, it is proposed that there will be other regions of the proinsulin molecule which will be implicated in the presentation of the conversion sites to the endoproteases. One such domain seems to lie just after the B-chain/C-peptide junction. Based upon nuclear magnetic resonance studies of proinsulin structure in solution, it has been proposed that a characteristic kink in the proinsulin molecule, referred to as the "CA knuckle", could be involved in presentation of the C-peptide/ A-chain conversion site [70]. The inspection of the hypothetical three-dimensional structures of many diverse proproteins does not reveal any peculiar domains aside from pairs of basic residues typically appearing in regions with a high probability of forming $\beta$-turns adjacent to those predicted to assume a highly ordered tertiary structure (i. e. $\alpha$-helix) [71]. The perturbation of these putative "presentation" domains of other prohormones does indeed inhibit their conversion [72]. Nature has provided us with an interesting situation for the direct comparison of the kinetics of conversion of two proinsulins in their natural setting. The two non-allelic rat insulin gene products differ at two residues in the C-peptide and two in the B-chain. Proinsulin I is known to be converted to insulin more rapidly than proinsulin II [73], and it seems logical to propose that this difference is due to one or more of the amino acid replacements which distinguish the two pro- 


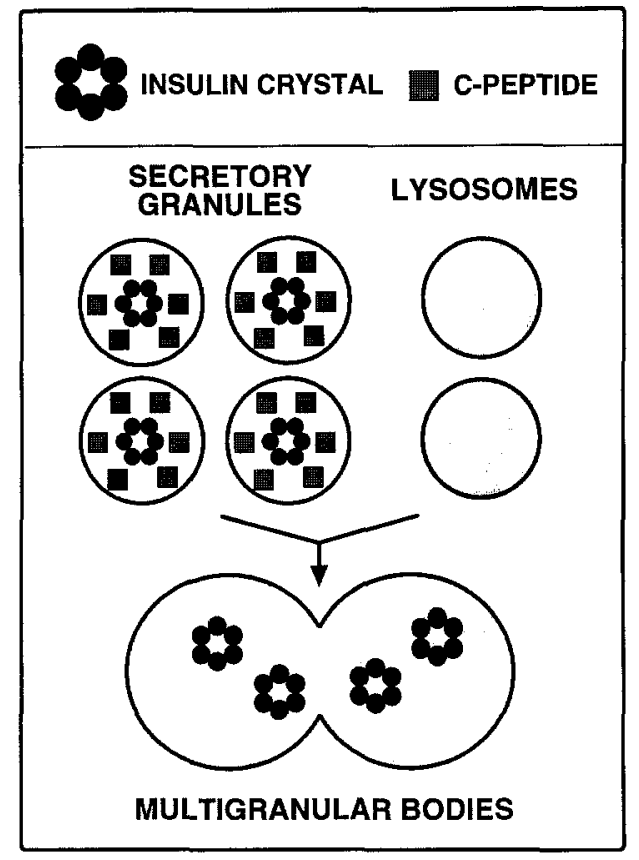

Fig.6. Model of insulin degradation in the Beta cell (crinophagy). Granules (containing equimolar amounts of insulin and C-peptide, and some unconverted proinsulin (not shown)) fuse with lysosomes to form multigranular bodies. Insulin, which is stored as a crystal in granules, is thought to remain in the crystal state in multigranular bodies and is degraded very slowly. C-peptide, by contrast, which is soluble in the granule, is degraded rapidly once introduced into the degradative compartment

insulins. Indeed, we have found [74] that cleavage at the B-chain/C-peptide junction of rat proinsulin II is unusually slow, suggesting that there is an interesting change in the presentation of this conversion site to the endoprotease.

\section{The crystallisation of insulin}

If insulin is not released by exocytosis of granule contents it can be degraded within the Beta cell [21]. Although the regulation of intra-Beta-cell insulin degradation is not well characterised, it is apparent that if release is decreased degradation is increased and vice versa $[21,75]$. It had been supposed for many years that insulin should be degraded within Beta cells by fusion of granules with lysosomes, a process referred to as crinophagy, and previously demonstrated in other secretory cells. This mechanism was confirmed by morphological studies showing the presence of both lysosomal proteases and insulin immunoreactive electron-dense cores (see below) in Beta-cell multigranular bodies [20].

Intriguingly, even if there was extensive degradation of insulin in the Beta cell, it was very slow compared with that seen for hormones in other cells $[20,21]$. The reason for this soon became apparent. It was first shown that insulin could be localised by immunocytochemistry to the electron dense cores of the multigranular bodies [20]. Cpeptide, although present, as expected, in granules, was not detectable in the multigranular bodies. It was sug- gested that insulin was degraded less rapidly than C-peptide within the multigranular bodies, and that this was due to stabilisation of insulin in the crystal state [20]. We subsequently performed experiments in vitro to confirm this hypothesis [76], and our working model is outlined in Figure 6.

Insulin is indeed believed to be stored within mature granules in the crystal state. Evidence for this is based upon high resolution electron microscopy revealing not only the angular shape of the electron-dense core of the Beta-cell granule but also striations within the core whose interval and symmetry resemble those of the insulin crystal grown in vitro [52]. Insulin immunoreactivity has, furthermore, been localised by immunocytochemical techniques to the dense core of the granules [3] and this has been confirmed biochemically [77].

The internal milieu of granules and lysosomes is thought to be quite similar; certainly mature secretory granules, just as lysosomes, are acidic organelles [78]. The insulin crystal would therefore be expected to be as stable in lysosomes as in the granule. During crinophagy, granules fuse with lysosomes and granule contents thus become exposed to lysosomal proteases. C-peptide and proinsulin, neither of which can crystallise (even though proinsulin has been shown to co-crystallise to a limited extent with insulin in vitro) will be degraded rapidly. The insulin crystal, by contrast, will have to be etched away within multigranular bodies and degradation should thus be extraordinarily slow. In addition to following the rates of degradation of crystalline insulin and soluble insulin or proinsulin in vitro [76] we have confirmed experimentally two predictions of this model in studies on crinophagy in islet Beta cells. The first of these studies showed that proinsulin which cannot be converted (after being modified during its biosynthesis by arginine and lysine analogues) and which will thus be unable to crystallise, is degraded more rapidly in Beta cells than is native insulin [79]. The second prediction of the model to be tested concerns the molar ratio of insulin: C-peptide in the Beta cell. Although this ratio will be $1: 1$ within granules (one molecule of proinsulin being converted to one each of insulin and C-peptide) it should be much higher in multigranular bodies. The overall insulin:C-peptide ratio in the Beta cell (reflecting the combined ratios in granules and multigranular bodies) should thus reflect the activity of the crinophagic pathway, and this is indeed found to be the case [80].

Of all the domains discussed in this Review, those involved in the oligomerisation (formation of the $\mathrm{Zn}$-hexamer) and crystallisation of insulin are the best characterised. This knowledge stems from X-ray diffraction studies of the insulin crystal [52]. We must assume that the behaviour of insulin within the granule is well represented by its behaviour in the test tube, despite the very obvious differences in chemical environment. The formation of the insulin crystal in the Beta-cellgranule depends upon a number of structural domains: those involved in association of monomers into dimers, the assembly of three dimers into the hexamer and, finally, the packing of hexamers into the crystal. These events and domains have been described in great detail elsewhere $[52,53]$ and will not be further discussed here. 


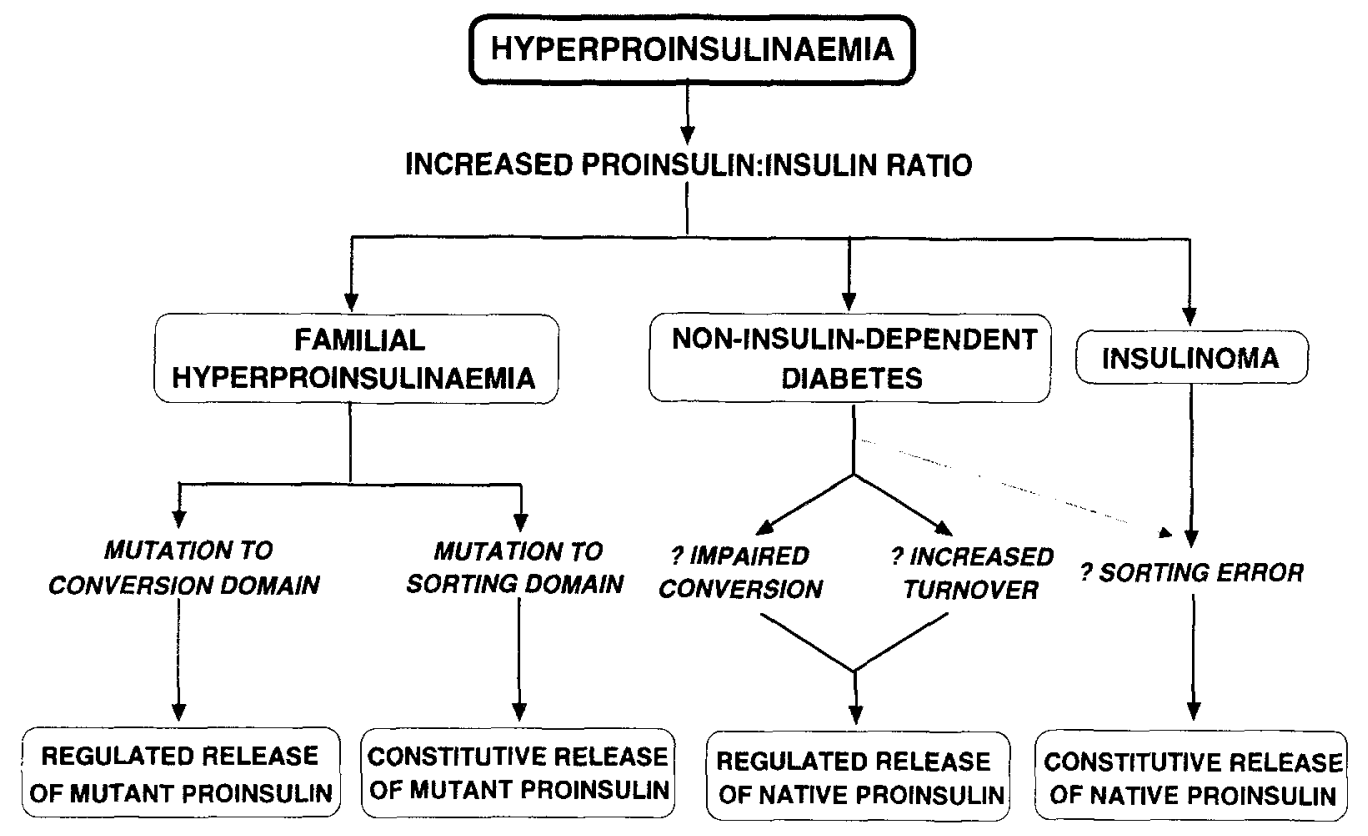

Fig. 7. Possible causes of hyperproinsulinaemia. Only clinical situations in which the amount of proinsulin relative to insulin in the circulation is elevated are considered. The examples and possible causes are not considered exhaustive Question marks indicate that the given explanation remains hypothetical. The dotted line linking hyperproinsulinaemia in diabetic patients to a defect in sorting indicates that this is the least likely explanation but may be an additional defect
Aside from stabilisation of insulin in multigranular bodies it is not clear what purpose the crystal serves. Indeed, stabilisation within the degradative compartment is in itself not of any obvious advantage to the organism since it will not be released from the cell in an intelligent or predictable fashion. Insulin is believed to crystallise in the majority of animal Beta-cells, but we have yet to understand the evolutionary advantages of being able to crystallise insulin in the Beta-cell granule. Indeed, crystallisation is not an obligatory feature of the insulin synthetic cascade since, as mentioned above, in guinea-pig insulin, B10 histidine is replaced with asparagine yet the Beta cells of these animals appear to be well granulated and replete with insulin.

\section{Proinsulin trafficking and processing in health and disease}

As mentioned earlier, in healthy rats (and, one presumes, humans) more than $99 \%$ of proinsulin is directed to the regulated secretory pathway [42]. The result is that fully processed insulin is the predominant product of the Beta cell, and its release is under tight regulation by secretagogues. Under what situations could one imagine a perturbation to this remarkably efficient process, and what would be the consequences? The following must be considered: (a) changes to the cellular machinery; (b) changes to proinsulin/insulin domains. In both cases the clinical symptom would be hyperproinsulinaemia, but the underlying causes would be quite different. One must also distinguish between hyperproinsulinaemia due to excessive, and uncontrolled, release of proinsulin via the constitutive pathway, and the regulated release (from granules) of non-converted proinsulin. These various possibilities are summarised in Figure 7. It is important to note that we are dealing here only with situations in which the ratio of proinsulin to insulin is unusually elevated, and that the clinical investigation of such syndromes is confounded by the relative rates (and mechanism) of clearance of insulin and its precursor. Insulin is, thus, cleared from the circulation predominantly by a receptor-mediated pathway (principally hepatic) whereas proinsulin, which is bound less avidly by the insulin receptor, is degraded essentially by non-receptor-mediated pathways (in the kidney) [81].

\section{Changes to the cellular sorting or conversion machinery}

Any defect in the ability of the Beta cell to target proinsulin to the regulated secretory pathway would be expected to result in an unusual proportion of the unprocessed prohormone being discharged rapidly after its synthesis via the constitutive pathway. Even though we now believe (see above) that the constitutive pathway may be able to entertain proinsulin conversion, this may not be true of all cells (our preliminary studies have been limited to hepatoma cells) and it is not expected that conversion would be extensive even if it occurred. The poorly regulated release of disproportionate amounts of proinsulin is a clinical situation encountered in many cases of insulinoma $[82,83]$. Indeed, there is evidence in vitro that transformation of Beta cells leads to an aberrantly active release of proinsulin via the constitutive pathway [84]. It is not known why transformed cells should be less able to direct prohormones to secretory granules than their native counterparts.

No example of hyperproinsulinaemia due to a genetic defect in the converting enzymes has yet been documented. The consequence would be the regulated release of proinsulin or of a conversion intermediate. Defective conversion could be due to a mutation to one of the enzymes (endoprotease or carboxypeptidase $\mathrm{H}$ ); it could equally arise from a defect in, for example, the granule proton pump, thereby preventing granule acidification and thus conversion. Since, however, both the conversion 
enzymes and the granule proton pump (and indeed all the elements of the conversion machinery in its broadest sense) are believed to be shared by most regulated secretory cells, such changes would lead to a generalised syndrome of "hyper-prohormonaemia" which would probably be incompatible with life. The one example in which familial hyperproinsulinaemia was initially proposed to be due a mutation of one of the proinsulin conversion enzymes [85] was subsequently shown to be caused by the partial diversion of B10 Asp proinsulin to the constitutive pathway (see above) $[49,50]$.

Unusually elevated proinsulin to insulin ratios are often encountered in the circulation of (Type 2) non-insulin-dependent diabetic patients [86-89]. Again, the reason for this is not known. It is possible that this altered ratio reflects a fundamental change to the Beta-cell conversion system, and it has been proposed that whatever this lesion may be, it could also be responsible for the amyloidosis encountered in the immediate surroundings of both insulinoma cells and islets in Type 2 diabetic patients $[90,91]$. The other possibility is that relatively more proinsulin than insulin is released from the Beta cell simply due to pressure on the cell for increased insulin production (due to peripheral insulin resistance and, on occasion, to a diminished Beta-cell mass). In this model, increased insulin turnover would reduce the residence time of any given proinsulin molecule so as to limit its chances of being completely converted. The observation that the relative hyperproinsulinaemia in these patients is in part due to elevated levels of conversion intermediates (and principally des 31.32 split proinsulin) [92] rather than intact proinsulin is quite in keeping with either model. It is to be hoped that the study of animal models of Type 2 diabetes (which allow access to the pancreas and its Beta cells) will help to clarify these important issues [93].

\section{Changes to proinsulin domains}

As discussed in detail above, even single amino acid substitutions in the sequence of proinsulin (or, indeed the signal peptide of preproinsulin) can perturb sorting or processing. To date the only (extremely rare) examples of naturally occurring mutations of this class are those involving changes to one of the basic residues at the sites of cleavage [66] and the infamous B10 Asp mutant [49, 50]. The clinical manifestations of such mutants will be hyperproinsulinaemia for all changes in which the mutant proinsulin actually survives its passage through the Golgi complex to a secretory vessel (whether vesicle or granule). Such hyperproinsulinaemia will be due either to mistargetting to the constitutive pathway (in which case proinsulin release will not be sensitive to secretagogues) or to incomplete or totally inhibited conversion of mutant proinsulin in granules (leading to the regulated release of proinsulin or conversion intermediates). Mutations which prevent the delivery of proinsulin to one of the secretory pathways (i.e. a change to the signal peptide or to a domain on proinsulin needed for correct folding of the molecule) would not be readily identified by the mere analysis of circulating insulin immunoreactive forms in humans, since such molecules would most probably be degraded within Beta cells without ever being released.

\section{Conclusions}

A complex interchange of molecular information underlies insulin production by the pancreatic Beta cell. Even if proinsulin structural domains are of obvious importance in this process, it is their interaction with the molecular machinery of the synthetic pathway which allows for efficient and regulated insulin release.

The study of the cell and molecular biology of insulin production will, it is hoped, lead to a better understanding of the defects responsible for aberrant Beta-cell function in disease. Even if insulin gene replacement therapy of diabetes remains a very distant goal, the combination of these studies on processing and trafficking with those focussing on the regulation of insulin gene expression, will certainly provide an essential first step in this direction [94].

Acknowledgements. My greatest debt is to the late Albert Renold whose scientific curiosity and intelligence were and remain a source of inspiration. His unique approach to life, and his generous and caring attitude towards his colleagues and friends (both in and out of the laboratory) should serve as an example to all who had the privilege of knowing him. Over the years, my work has been supported by the Swiss National Science Fund, the National Institutes of Health, the Juvenile Diabetes Foundation International, the Greenwall Foundation, the Faculty of Medicine of the University of Geneva, Joslin Diabetes Center and the Louis Jeantet Medical Foundation. I am most indebted to these organisations as I am to the following individuals for their leadership, friendship, help and encouragement: Claes Wollheim, Daniel Mintz, Gordon Weir and Ron Kahn. I should also like to thank Lydia Villa-Komaroff and David Gross for sharing with me their expertise in molecular biology. My collaboration with Lelio Orci has inspired much of my work. He is both a demanding and challenging teacher and a faithful friend. I thank him for these qualities and for continuing to share so many innovative ideas with me. Finally, I thank Caty Meyer who has been responsible for performing many of the experiments mentioned, Marie-José Tissières for help in typing this manuscript, and Dominique Rouiller for his useful comments. If space prevents me from mentioning the many other collaborators (past and present) with whom it has been my pleasure to work, I am nonetheless also greatly indebted to them.

\section{References}

1. Palade $\mathbf{G}$ (1975) Intracellular aspects of the process of protein synthesis. Science 189:347-358

2. Orci L (1982) Macro- and micro-domains in the endocrine pancreas. Diabetes 31: 538-565

3. Orci $L(1985)$ The insulin factory: a tour of the plant surroundings and a visit to the assembly line. Diabetologia 28: 528-546

4. Steiner DF, Bell GI, Tager HS (1989) Chemistry and biosynthesis of pancreatic protein hormones. In: DeGroot LJ (ed) Endocrinology. WB Sanders, Philadelphia London Toronto Montreal Sydney Tokyo, pp 1263-1289

5. Selden RF, Skoskiewicz MJ, Russel PS, Goodman HM (1987) Regulation of insulin-gene expression. N Engl J Med 317: 10671076

6. Welsh M (1989) Glucose regulation of insulin gene expression. Diab Metab 15: 367-371

7. Serafini T, Stenbeck G, Brecht A et al. (1991) A coat subunit of Golgi-derived non-clathrin-coated vesicles with homology to the clathrin-coated vesicle coat protein $\beta$-adaptin. Nature 349:215220 
8. Howell SL (1972) Role of ATP in the intracellular translocation of proinsulin and insulin in the rat pancreatic B-cell. Nat New Biol 235: 85-86

9. Malaisse-Lagae F, Amherdt M, Ravazzola M et al. (1979) Role of microtubules in the synthesis, conversion, and release of (pro)insulin. J Clin Invest 63: 1284-1296

10. Balch WE (1990) Molecular dissection of early stages of the eukaryotic secretory pathway. Curr Opin Cell Biol 2: 634-641

11. Clary DO, Griff IC, Rothman JE (1990) SNAPs, a family of NSF attachment proteins involved in intracellular membrane fusion in animals and yeast. Cell 61: 709-721

12. Clary DO, Rothman JE (1990) Purification of three related peripheral membrane proteins needed for vesicular transport. J Biol Chem 265: 10109-10117

13. Beckers CJM, Block MR, Glick BS, Rothman JE, Balch WE (1989) Vesicular transport between the endoplasmic reticulum and the Golgi stack requires the NEM-sensitive fusion protein. Nature 339: 397-398

14. Griffiths G, Simons K (1986) The trans Golgi network: sorting at the exit site of the Golgi complex. Science 234: 438-443

15. Orci L, Ravazzola M, Amherdt M et al. (1987) The trans-most cisternae of the Golgi complex: a compartment for sorting of secretory and plasma membrane proteins. Cell 51:1039-1051

16. Halban PA (1990) Proinsulin trafficking and processing in the pancreatic B-cell. Trends Endocrinol Metab 1:261-265

17. Kelly R (1985) Pathways of protein secretion in eukaryotes. Science 230: 25-32

18. Pfeffer SR, Rothman JE (1987) Biosynthetic protein transport and sorting by the endoplasmic reticulum and Golgi. Ann Rev Biochem 56: 829-852

19. Orci L, Ravazzola M, Storch J-J, Anderson RGW, Vassalli J-D, Perrelet A (1987) Proteolytic maturation of insulin is a postGolgi event which occurs in acidifying clathrin-coated secretory vesicles. Cell 49: 865-868

20. Orci L, Ravazzola M, Amherdt M et al. (1984) Insulin, not Cpeptide (proinsulin), is present in crinophagic bodies of the pancreatic B-cell. J Cell Biol 98: 222-228

21. Halban PA, Wollheim CB (1980) Intracellular degradation of insulin stores by rat pancreatic islets in vitro. J Biol Chem 255: 6003-6006

22. Karrenbauer A, Jeckel D, Just W et al. (1990) The rate of bulk flow from the Golgi to the plasma membrane. Cell 63:259-267

23. Acton SL, Brodsky FM (1990) Predominance of clathrin light chain $\mathrm{LC}_{b}$ correlates with the presence of a regulated secretory pathway. J Cell Biol 111: 1419-1426

24. Davidson HW, Rhodes CJ, Hutton JC (1988) Intraorganellar calcium and $\mathrm{pH}$ control proinsulin cleavage in the pancreatic $\beta$ cell via two distinct site-specific endopeptidases. Nature 333: 93-96

25. Hutton JC, Peshavaria M (1982) Proton-translocating $\mathrm{Mg}^{2+}$-dependent ATPase activity in insulin-secretory granules. Biochem J 204: 161-170

26. Rhodes CJ, Lucas CA, Mutkoski RL, Orci L, Halban PA (1987) Stimulation by ATP of proinsulin to insulin conversion in isolated rat pancreatic islet secretory granules. J Biol Chem 262: 10712-10717

27. Orci L, Halban PA, Amherdt M, Ravazzola M, Vassalli J-D, Perrelet A (1984) Nonconverted, amino acid analog-modified proinsulin stays in a Golgi-derived clathrin-coated membrane compartment. J Cell Biol 99: 2187-2192

28. Brennan SO, Carrell RW (1978) A circulating variant of human proalbumin. Nature 274: 908-909

29. Yoshimasa Y, Seino S, Whittaker J et al. (1988) Insulin-resistant diabetes due to a point mutation that prevents insulin proreceptor processing. Science 240: 784-787

30. Brennan SO, Peach RJ (1988) Calcium-dependent KEX2-like protease found in hepatic secretory vesicles converts proalbumin to albumin. FEBS Lett 229: 167-170

31. Thomas G, Thorne BA, Thomas L et al. (1988) Yeast KEX2 endopeptidase correctly cleaves a neuroendocrine prohormone in mammalian cells. Science 241: 226-230
32. Walter P, Lingappa VR (1986) Mechanism of protein translocation across the endoplasmic reticulum membrane. Ann Rev Cell Biol 2: 499-516

33. Rapoport TA (1990) Protein transport across the ER membrane. Trends Biochem Sci 15: 355-358

34. von Heijne $G$ (1985) Signal sequences. The limits of variation. J Mol Biol 184: 99-105

35. Randall LL, Hardy SJS (1989) Unity in function in the absence of consensus in sequence: role of leader peptides in export. Science 243: $1156-1159$

36. Wiren KM, Ivashkiv L, Ma P, Freeman MW, Potts JT Jr, Kronenberg HM (1989) Mutations in signal sequence cleavage domain of preproparathyroid hormone alter protein translocation, signal sequence cleavage, and membrane-binding properties. Mol Endocrinol 3: 240-250

37. Lippincott-Schwartz J, Bonifacino JS, Yuan LC, Klausner RD (1988) Degradation from the endoplasmic reticulum. Disposing of newly synthesized proteins. Cell $54: 209-220$

38. Pelham HRB (1989) Heat shock and the storing of luminal ER proteins. EMBO J 8: 3171-3176

39. Landry SJ, Gierasch LM (1991) Recognition of nascent polypeptides for targeting and folding. Trends Biochem Sci 16: 159_ 163

40. Rothman JE (1989) Polypeptide chain binding proteins: catalysts of protein folding and related processes in cells. Cell 59: 591-601

41. Freedman RB (1989) Protein disulfide isomerase: multiple roles in the modification of nascent secretory proteins. Cell 57:10691072

42. Rhodes CJ, Halban PA (1987) Newly synthesized proinsulin/insulin and stored insulin are released from pancreatic B cells predominantly via a regulated, rather than a constitutive, pathway. J Cell Biol 105: 145-153

43. Orci L, Ravazzola M, Perrelet A (1984) (Pro)insulin associates with Golgi membranes of pancreatic B cells. Proc Natl Acad Sci USA 81:6743-6746

44. Chung KN, Walter P, Aponte GW, Moore HPH (1989) Molecular sorting in the secretory pathway. Science 243: 192-197

45. Moore HPH, Walker MD, Lee F, Kelly RB (1983) Expressing a human proinsulin cDNA in a mouse ACTH secreting cell. Intracellular storage, proteolytic processing and secretion on stimulation. Cell 35: 531-538

46. Kizer JS, Tropsha A (1991) A motif found in propeptides and prohormones that may target them to secretory vesicles. Biochem Biophys Res Commun 174: 586-592

47. Tooze J, Kern HF, Fuller SD, Howell KE (1989) Condensationsorting events in the rough endoplasmic reticulum of exocrine pancreatic cells. J Cell Biol 109: 35-50

48. Powell SK, Orci L, Craik CS, Moore HPH (1988) Efficient targeting to storage granules of human proinsulins with altered propeptide domain. J Cell Biol 106: 1843-1851

49. Carroll RJ, Hammer RE, Chan SJ, Swift HH, Rubenstein $\mathrm{AH}$, Steiner DF (1988) A mutant human proinsulin is secreted from islets of Langerhans in increased amounts via an unregulated pathway. Proc Nati Acad Sci USA 85: 8943-8947

50. Gross DJ, Halban PA, Kahn CR, Weir GC, Villa-Komaroff L (1989) Partial diversion of a mutant proinsulin (B10 aspartic acid) from the regulated to the constitutive secretory pathway in transfected AtT-20 cells. Proc Natl Acad Sci USA 86: 4107-4111

51. Quinn D, Orci L, Ravazzola M, Moore HPH (1991) Intracellular transport and sorting of mutant human proinsulins that fail to form hexamers. J Cell Biol 113: 987-996

52. Blundell T, Dodson G, Hodgkin D, Mercola D (1972) Insulin: the structure in the crystal and its reflection in chemistry and biology. Adv Protein Chem 26:279-402

53. Emdin SO, Dodson GG, Cutfield JM, Cutfield SM (1980) Role of zinc in insulin biosynthesis. Some possible zinc-insulin interactions in the pancreatic B-cell. Diabetologia 19:174-182

54. Schwartz GP, Burke GT, Katsoyannis PG (1987) A superactive insulin: [B10-aspartic acid] insulin (human). Proc Natl Acad Sci USA 84: 6408-6411 
55. Brange J, Ribel U, Hansen JF et al. (1988) Monomeric insulins obtained by protein engineering and their medical implications. Nature 333: 679-682

56. Ferber S, Gross DJ, Villa-Komaroff L et al. (1991) Heterogeneity of expression and secretion of native and mutant $\left[\mathrm{Asp}^{\mathrm{B} 10}\right]$ insulin in AtT20 cells. Mol Endocrinol 5: 319-326

57. Hutton JC (1989) The insulin secretory granule. Diabetologia 32: $271-281$

58. Gerdes HH, Rosa P, Phillips E et al. (1989) The primary structure of human secretogranin II, a widespread tyrosine-sulfated secretory granule protein that exhibits low $\mathrm{pH}$ - and calcium-induced aggregation. J Biol Chem 264: 1209-1215

59. Tooze SA, Huttner WB (1990) Cell-free protein sorting to the regulated and constitutive secretory pathways. Cell 60: 837847

60. Davidson HW, Hutton JC (1987) The insulin-secretory-granule carboxypeptidase $\mathrm{H}$. Purification and demonstration of involvement in proinsulin processing. Biochem J 245: 575-582

61. Roebroek AJM, Schalken JA, Leunissen JAM, Onnekink C, Bloemers HPJ, Van de Ven WJM (1986) Evolutionary conserved close linkage of the c-fes/fps proto-oncogene and genetic sequences encoding a receptor-like protein. EMBO J 5: 2197-2202

62. Smeekens SP, Steiner DF (1990) Identification of a human insulinoma cDNA encoding a novel mammalian protein structurally related to the yeast dibasic processing protease Kex2. J Biol Chem 265: 2997-3000

63. Smeekens SP, Avruch AS, LaMendola J, Chan SJ, Steiner DF (1991) Identification of a cDNA encoding a second putative prohormone convertase related to PC2 in AtT20 cells and islets of Langerhans. Proc Natl Acad Sci USA 88: 340-344

64. Halban PA (1982) Inhibition of proinsulin to insulin conversion in rat islets using arginine and lysine analogs. Lack of effect on rate of release of modified products. J Biol Chem 257: $13177-$ 13180

65. Docherty K, Rhodes CJ, Taylor NA, Shennan KEJ, Hutton JC (1989) Proinsulin endopeptidase substrate specificities defined by site-directed mutagenesis of proinsulin. J Biol Chem 264: $18335-18339$

66. Steiner DF, Tager HS, Chan SJ, Nanjo K, Sanke T, Rubenstein AH (1990) Lessons learned from molecular biology of insulingene mutations. Diab Care 13: 600-609

67. Gross DJ, Villa-Komaroff L, Kahn CR, Weir GC, Halban PA (1989) Deletion of a highly conserved tetrapeptide sequence of the proinsulin connecting peptide (C-peptide) inhibits proinsulin to insulin conversion by transfected pituitary corticotroph (AtT20) cells. J Biol Chem 264: 21486-21490

68. Mains RE, Eipper BA (1990) The tissue-specific processing or pro-ACTH/endorphin. Trends Endocrinol Metab 1:388-394

69. Thorne BA, Thomas G (1990) An in vivo characterization of the cleavage site specificity of the insulin cell prohormone processing enzymes. J Biol Chem 265: 8436-8443

70. Weiss MA, Frank BH, Khait I et al. (1990) NMR and photoCIDNP studies of human proinsulin and prohormone processing intermediates with application to endopeptidase recognition. Biochemistry 29: 8389-8401

71. Rholam M, Nicolas P, Cohen P (1986) Precursors for peptide hormones share common secondary structures forming features at the proteolytic processing sites. FEBS Lett 207:1-6

72. Brakch N, Boussetta H, Rholam M, Cohen P (1989) Processing endoprotease recognizes a structural feature at the cleavage site of peptide prohormones. J Biol Chem 264: 15912-15916

73. Gishizky ML, Grodsky GM (1987) Differential kinetics of rat insulin I and II processing in rat islets of Langerhans. FEBS Lett 223: $227-231$

74. Sizonenko SV, Halban PA (1991) Differential rates of conversion of rat proinsulin I and II. Biochem J 278: 621-625

75. Halban PA, Renold AE (1983) Influence of glucose on insulin handling by rat islets in culture. A reflection of integrated changes in insulin biosynthesis, release, and intracellular degradation. Diabetes 32: 254-261
76. Halban PA, Mutkoski R, Dodson G, Orci L (1987) Resistance of the insulin crystal to lysosomal proteases: implications for pancreatic B-cell crinophagy. Diabetologia 30: 348-353

77. Michael J, Carroll R, Swift HH, Steiner DF (1987) Studies on the molecular organization of rat insulin secretory granules. J Biol Chem 262: 16531-16535

78. Orci L, Ravazzola M, Amherdt M et al. (1986) Conversion of proinsulin to insulin occurs coordinately with acidification of maturing secretory vesicles. J Cell Biol 103: 2273-2281

79. Halban PA, Amherdt M, Orci L, Renold AE (1984) Proinsulin modified by analogues of arginine and lysine is degraded rapidly in pancreatic B-cells. Biochem J 219: 91-97

80. Rhodes CJ, Halban PA (1988) The intracellular handling of insulin-related peptides in isolated pancreatic islets. Evidence for differential rates of degradation of insulin and C-peptide. Biochern J 251: 23-30

81. Polonsky KS, Rubenstein AH (1989) The kinetics and metabolism of insulin, proinsulin, and C-peptide. In: DeGroot LJ (ed) Endocrinology. WB Sanders, Philadelphia London Toronto Montreal Sydney Tokyo, pp 1304-1317

82. Melani F, Ryan WG, Rubenstein AH, Steiner DF (1970) Proinsulin secretion by a pancreatic beta-cell adenoma. N Engl J Med 283: 713-719

83. Gorden P, Sherman B, Roth J (1971) Proinsulin-like component of circulating insulin in the basal state and in patients and hamsters with islet cell tumours. J Clin Invest 50: 2113-2122

84. Gold G, Gishzky ML, Chick WL, Grodsky GM (1984) Contrasting patterns of insulin biosynthesis, compartmental storage, and secretion. Diabetes 33: 556-561

85. Gruppuso PA, Gorden P, Kahn CR, Cornblath M, Zeller WP, Schwartz R (1984) Familial hyperproinsulinemia due to a proposed defect in conversion of proinsulin to insulin. $\mathrm{N}$ Engl J Med 311:629-634

86. Duckworth WC, Kitabchi AE, Heinemann M (1972) Direct measurement of plasma proinsulin in normal and diabetic subjects. Am J Med 53: 418-427

87. Mako ME, Starr JI, Rubenstein AH (1977) Circulating proinsulin in patients with maturity onset diabetes. Am J Med 63: 865869

88. Ward WK, LaCava EC, Paquette TL, Beard JC, Wallum BJ, Porte D Jr (1987) Disproportionate elevation of immunoreactive proinsulin in Type 2 (non-insulin-dependent) diabetes mellitus and in experimental insulin resistance. Diabetologia 30: 698-702

89. Yoshioka N, Kuzuya T, Matsuda A, Taniguchi M, Iwamoto Y (1988) Serum proinsulin levels at fasting and after oral glucose load in patients with Type 2 (non-insulin-dependent) diabetes mellitus. Diabetologia 31: 355-360

90. Porte D Jr, Kahn SE (1989) Hyperproinsulinemia and amyloid in NIDDM. Clues to etiology of islet $\beta$-cell dysfunction? Diabetes 38: 1333-1336

91. Porte D Jr (1991) $\beta$-cells in type II diabetes mellitus. Diabetes 40: $166-180$

92. Nagi DK, Hendra TJ, Ryle AJ et al. (1990) The relationships of concentrations of insulin intact proinsulin and 32-33 split proinsulin with cardiovascular risk factors in Type 2 (non-insulindependent) diabetic subjects. Diabetologia 33:532-537

93. Leahy JL, Halban PA, Weir GC (1991) Relative hypersecretion of proinsulin in a rat model of non-insulin-dependent diabetes mellitus. Diabetes 40: 985-989

94. Schnetzler B, Ferber S, Vollenweider F et al. (1991) Theoretical aspects of gene therapy of diabetes. In: Shafrir E (ed) Frontiers in diabetes research II. Lessons from animal diabetes III. SmithGordon, London, pp 618-622

Dr.P.A.Halban

Laboratoires de Recherche Louis Jeantet

Centre Mêdical Universitaire

1, rue Michel Servet

CH-1211 Geneva 4

Switzerland 